\title{
The effects of vasectomy on testicular metabolism in the guinea-pig
}

\author{
S. S. Howards, C. J. Flickinger, D. W. Noller \\ and W. B. Panko \\ Departments of Urology, Physiology, and Anatomy, University of Virginia School of Medicine, \\ Charlottesville, Virginia 22901, U.S.A.
}

\begin{abstract}
Summary. The effects of vasectomy on testicular DNA production were studied in guinea-pigs at 2 weeks and 2 and 6 months after surgery. By 6 months, vasectomy had resulted in lower testicular weight and absolute DNA, RNA and protein contents, although RNA and DNA concentrations/protein were unchanged. Incorporation of thymidine into the testis had decreased by 2 weeks after vasectomy, and continued to do so unless the ductal system subsequently ruptured and formed a granuloma when thymidine incorporation returned to normal control levels. It is suggested that in the guinea-pig vasectomy alters spermatogenesis by reducing testicular DNA synthesis.
\end{abstract}

\section{Introduction}

The extensive, conflicting, experimental literature which examines the effect of vasectomy on spermatogenesis has recently been reviewed by several authors (Neaves, 1975; Bedford, 1976; Heidger \& Sawatzke, 1977). The consensus is that vasectomy per se does not significantly affect spermatogenesis in the rat, bull or monkey, impairs spermatogenesis in the guinea-pig, and results in changes in the seminiferous epithelium of the rabbit after about 1 year. In the dog, alterations in the seminiferous tubules are followed by a recovery. However, for most of these species, there are studies which show different results (see reviews above).

The majority of investigations into the effects of vasal obstruction on spermatogenesis have measured testis weight and/or seminiferous epithelial histology. These are static anatomical methods, and because of the conflicting results in the literature we decided to study the influence of unilateral vasectomy on spermatogenesis in the guinea-pig by a dynamic measure of DNA synthesis, i.e. the incorporation of tritiated thymidine into testicular DNA. We also investigated the testicular content of DNA, RNA and protein at intervals after vasectomy.

\section{Materials and Methods}

Mature 3-month-old Hartley-strain male guinea-pigs (550-600 g) were allowed to acclimatize to the vivarium for 2 weeks and were then divided into experimental (E) and control (C) groups. The animals in Group $\mathrm{E}$ were anaesthetized with ether and, under sterile conditions through a low mid-line abdominal incision, a segment of the left vas deferens was excised and each end was tied with 3-0 silk. The right vas deferens was exposed in a similar manner as a sham procedure. All the animals were subsequently examined twice a week and any with scrotal swelling, inflammation or abdominal testis were excluded from the study. The control animals were divided into two sub-groups: Group $\mathrm{C} 1$ consisted of 3-month-old animals that were killed soon after acclimatization at a weight of 550-600 g and Group C2 contained older animals that were killed 
5 months after vasectomy when their weight had increased to about $1200 \mathrm{~g}$. The Group E animals were killed at 2 weeks and 2 or 6 months after vasectomy. The 2-week and 2-month Group E animals were compared to those in Group $\mathrm{C} 1$ and the 6-month Group E animals were compared to those in Group C2. In addition, vasectomized guinea-pigs were killed 1, 3, 4, 5 and 12 months after operation. They were not compared with control animals because there were only 1 or 2 animals at each age and no appropriate control group for the 12-month-old guinea pigs. However, DNA data from these animals are included in Text-fig. 1. The sham-operated side of the experimental animals was also compared with the vasectomized side.

Each animal was anaesthetized with ether $4 \mathrm{~h}$ before death and $75 \mu \mathrm{Ci}$ tritiated thymidine (sp. act. $58.5 \mathrm{Ci} / \mathrm{mmol}$ : ICN Radiochemicals Inc., Irvine, California) $/ 100 \mathrm{~g}$ body weight were injected $(1 \mathrm{mCi} / \mathrm{ml})$ into the heart. The $4 \mathrm{~h}$ period was used because previous studies had demonstrated that a stable testicular level of tritiated thymidine/ $\mu \mathrm{g}$ DNA was achieved at this time (Panko, Noller \& Howards, 1977).

After killing the animal with an overdose of intracardiac pentobarbitone sodium, the testes and cord structures were carefully examined through a scrotal incision. If a para-epididymal mass was noted, its contents were examined microscopically to determine whether it was a spermatic granuloma. A sample of the testis was taken and fixed in Bouin's fluid for routine histological study. The incorporation of $\left[{ }^{3} \mathrm{H}\right]$ thymidine into testicular DNA was determined from a sample of testis and the rest of the testicular parenchyma was weighed and used for isolation and measurements of DNA, RNA and protein (see Panko et al., 1977).

Student's $t$ test was used for statistical comparison of the differences between the control and experimental groups. Paired data analysis was utilized to compare the vasectomized testes with the sham-operated gonad of the same animal.

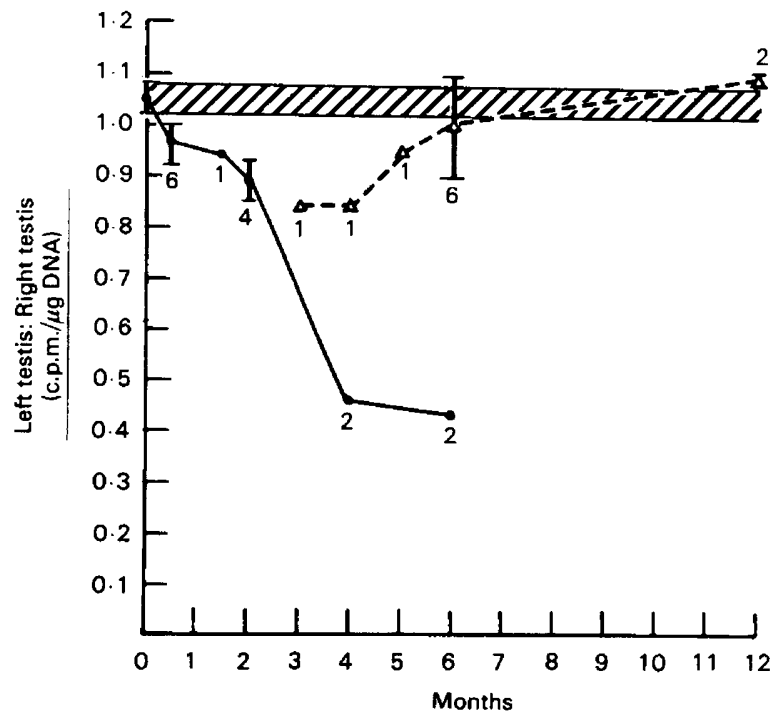

Text-fig. 1. The incorporation of $\left[{ }^{3} \mathrm{H}\right]$ thymidine into the testicular tissue of the guinea-pig after vasectomy, expressed as a ratio of the uptake on the left side, the side of the vasectomy, and the uptake on the sham-operated side. The ratio for 18 control animals (Groups C1 and C2) is indicated by the hatched bar. The numbers of animals at each point are indicated: represents animals in which there was no granuloma formation or rupture and $\Delta$ represents those animals in which these did occur. 


\section{Results}

The results are presented in Table 1 . There were no differences between the left and right sides of the intact control animals and the values were therefore combined. By 6 months after surgery, the testes on the side of the vasectomy were lighter than those in the age-matched control animals $(P<0.02)$ and those on the sham-operated side $(P<0.01)$. There was no significant difference among the groups in the amount of DNA or RNA/g testis weight. However, because of the differences in testis weight, there was less total DNA and RNA in the left testes at 6 months after vasectomy $(P<0.01)$. There was slightly, but significantly, more protein/g testis in the left testis than the right at 2 weeks $(P<0.01)$ and 2 months $(P<0.05)$ after surgery, and less total protein in the left testis at 6 months after the operation $(P<0.01)$.

As shown in Text-fig. 1, the incorporation of tritiated thymidine into DNA decreased in the testis on the side of vasectomy. However, if a granuloma or an epididymal rupture occurred between 2 and 4 months, the incorporation of $\left[{ }^{3} \mathrm{H}\right]$ thymidine into DNA gradually returned to control values at 6 months.

\section{Discussion}

There are conflicting observations in the literature regarding the effects of unilateral vasectomy on the weight of the testis: Moore (1926) showed no change in testicular weight in the dog after vasectomy but Kothari \& Pardnani (1967) reported a decrease in testicular weight in the guineapig which became statistically significant 6 months after surgery. This decrease in weight could be secondary to a loss of fluid, inhibition of spermatogenesis and degeneration of the seminiferous epithelium or a loss of interstitial tissue. By monitoring DNA, RNA and protein in the testis at various times after vasectomy and by using a dynamic measurement of testicular DNA synthesis (thymidine incorporation into DNA), we gained additional insight into the effects of vasoligation on the male gonad. The absolute amounts of DNA, RNA and protein eventually decreased in the testis on the side of vasectomy, although there was no change in the fractional distribution of DNA and RNA in these testes. This is in agreement with Kwart \& Coffey (1973) who studied prepubertal rats with spermatic granulomata and found no change in the fractional distribution of testicular DNA, RNA and protein between the vasodilated and contralateral testis.

The thymidine incorporation results demonstrated that vasectomy was followed by an immediate and a gradually increasing reduction in DNA synthesis. This decrease in DNA synthesis is primarily due to an inhibition of spermatogenesis (Panko et al., 1977). Therefore, the decreased rate of testicular DNA synthesis after unilateral vasectomy suggests that there was a reduction in the multiplication of spermatogonia and consequently in the number leaving the stem cell population and entering into the maturation process, and in DNA synthesis in preleptotene primary spermatocytes preparing for meiosis. A decreased intensity of labelling of cells might also have contributed to the reduced incorporation of $\left[{ }^{3} \mathrm{H}\right]$ thymidine into the DNA. The deficit appears to be reversible, however, because if the male duct system ruptured, thus permitting the escape of spermatozoa into a granuloma and relieving the obstruction, then DNA synthesis returned to normal levels. Between 2 and 4 months after surgery appeared to be a crucial time; either the vas-epididymal system ruptured and the DNA synthesis returned to control values (even though the total weight, DNA, RNA and protein content remained lower than in the contralateral testis), or the vas deferens and epididymis remained totally obstructed for the duration of the experiment and the DNA synthesis continued to decrease. Testicular DNA metabolism was, therefore, unequivocally related to the presence of obstruction.

It is possible that unilateral vasectomy alters the contralateral testis through an immunological or humoral mechanism. However, in this study, there were no differences between the testes on the side of the sham-operation in the unilaterally vasectomized animals and 


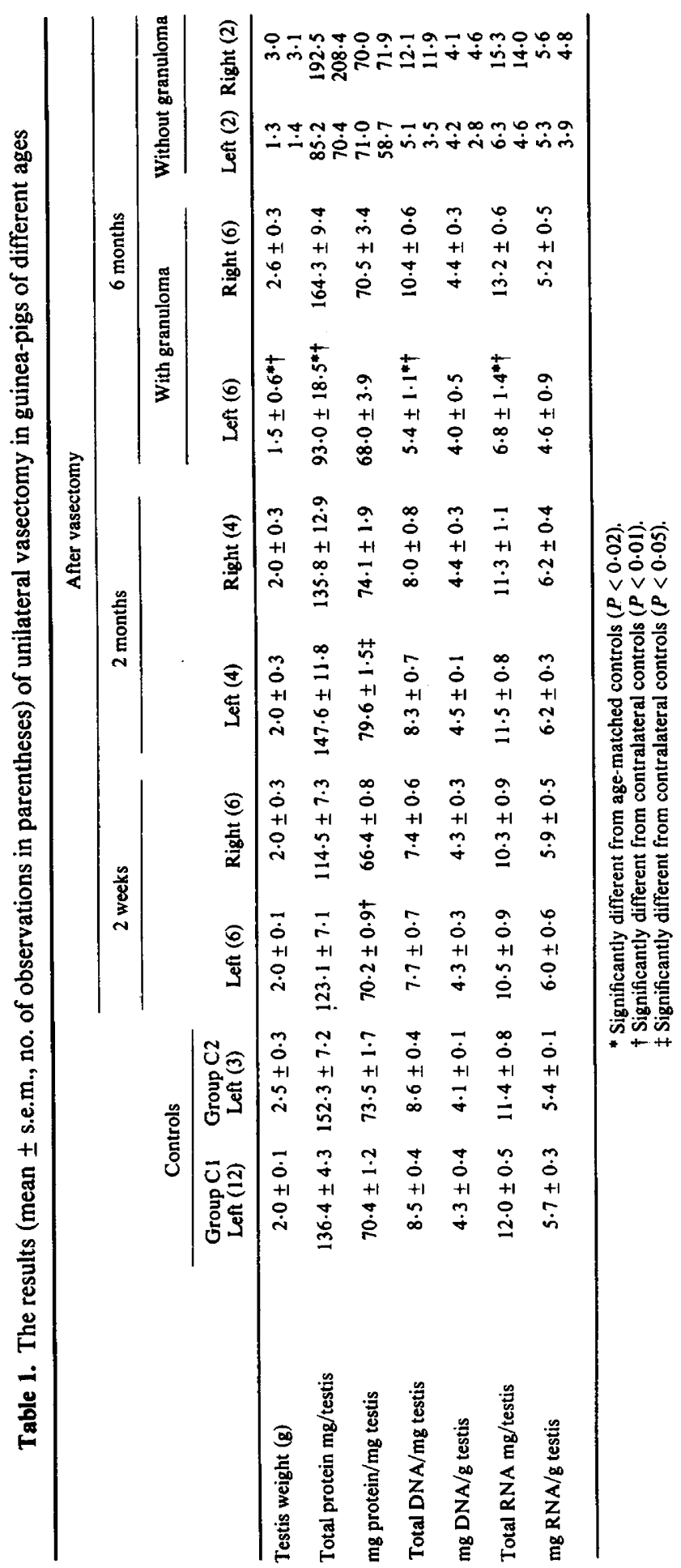


those of the control guinea-pigs, suggesting that the former were not significantly affected by the contralateral surgery.

The work was supported by Grant HD09490-02, Contract 72-2770 and the Career Development A ward 1-K04-HD00108-01 from the National Institutes of Health.

\section{References}

Bedford, J.M. (1976) Adaptations of the male reproductive tract and the fate of spermatozoa following vasectomy in the rabbit, rhesus monkey, hamster, and rat. Biol. Reprod. 14, 219-221.

Heidger, P.M. \& Sawatzke, C.L. (1977) The structural effects of vasectomy upon the male reproductive system. In The Male Reproductive System, pp. 131153. Eds R. D. Yates \& M. Gordon. Masson, New York.

Kothari, M.L. \& Pardnani, D.S. (1967) Temporary sterilization of the male by intra intravasal contraceptive device (IVCD). Indian J. Surg. 29, 357363.
Kwart, A.M. \& Coffey, D.S. (1973) Sperm granulomas: an adverse effect of vasectomy. J. Urol. 110, 416422.

Moore, C.R. (1926) The biology of the mammalian testis and scrotum. $Q$. Rev. Biol. 1, 4-50.

Neaves, W.B. (1975) Biological aspects of vasectomy. In Handbook of Physiology, Vol. 5, Section 7, Endocrinology, pp. 382-404. Eds D. W. Hamilton \& R. O. Greep, Am. Physiol. Soc., Washington, D.C.

Panko, W.B., Noller, D.W. \& Howards, S.S. (1977) A simplified method for the quantitation of spermatogenesis in the guinea-pig. J. Reprod. Fert. 51, $123-125$.

Received 3 July 1978 